\title{
Estrogen regulates the proliferation and inflammatory expression of primary stromal cell in benign prostatic hyperplasia
}

\author{
Bo Chen ${ }^{1,2 \#}$, Dehong Cao, ${ }^{1,2 \#}$, Zeyu Chen ${ }^{1,2}$, Yin Huang ${ }^{1,2}$, Tianhai Lin ${ }^{1,2}$, Jianzhong Ai ${ }^{1,2}$, Liangren Liu ${ }^{1,2}$, \\ Qiang Wei ${ }^{1,2}$
}

${ }^{1}$ Department of Urology, ${ }^{2}$ Institution of Urology, West China Hospital, Sichuan University, Chengdu 610041, China

Contributions: (I) Conception and design: L Liu, Q Wei; (II) Administrative support: None; (III) Provision of study materials or patients: T Lin, J Ai; (IV) Collection and assembly of data: B Chen, D Cao; (V) Data analysis and interpretation: Z Chen, Y Huang, T Lin, J Ai; (VI) Manuscript writing: All authors; (VII) Final approval of manuscript: All authors.

\#These authors contributed equally to this work.

Correspondence to: Liangren Liu; Qiang Wei. Department of Urology, West China Hospital, Sichuan University, No. 37, Guoxue Alley, Chengdu 610041, China. Email: liuliangren@scu.edu.cn; weiqiang933@126.com.

Background: To investigate the expression of estrogen receptor (ER) in prostate tissues of benign prostatic hyperplasia $(\mathrm{BPH})$ individuals, and the effects of estrogen regulating the proliferation and inflammatory expressions of primary prostate stromal cells in BPH.

Methods: A total of 44 human BPH prostate tissues were collected to explore the expression of ER by immunohistochemistry (IHC). Cell proliferation, mRNA and protein expressions were analyzed in primary prostate stromal cells treated with estrogen or estrogen plus fulvestrant through cell count kit-8 (CCK-8) assay, quantitative real-time polymerase chain reaction (qPCR), IHC and western blot, respectively.

Results: Firstly, ER $\beta$ was positive, and ER $\alpha$ was negative in the transition zone of prostate among all the 44 individuals with BPH. Secondly, the effects could be partially inhibited by fulvestrant, of estrogen promoting the proliferation of primary prostate stromal cells cultured in dulbecco's modified eagle medium (DMEM) supplemented with $2 \%$ fetal bovine serum (FBS). Thirdly, estrogen up-regulates the mRNA levels of C-C chemokine receptor type 3 (CCR3), CD40 ligand (CD 40L), C-X-C motif chemokine ligand 9 (CXCL9) and interleukin 10 (IL10), and down-regulates the mRNA levels of C-C chemokine receptor type 4 (CCR4) and interleukin 17C (IL17C). Then, the protein expressions of CCR3, CCR4, CD40L, IL10 and IL17C are positive, and CXCL9 is negative in the third-generation primary prostate stromal cells. Finally, the effects could be partially inhibited by fulvestrant, of estrogen up-regulating the protein levels of CD40L and IL10.

Conclusions: The expressions of ER in human BPH prostate tissues are zone-dependent. Estrogen promoting the proliferation of primary prostate stromal cells cultured in DMEM supplemented with $2 \%$ FBS. The expressions of CCR3, CCR4, CD 40L, IL17C, CXCL9 and IL10 are regulated by estrogen in primary prostate stromal cells.

Keywords: Estrogen; benign prostatic hyperplasia (BPH); estrogen receptor (ER); inflammatory

Submitted Oct 28, 2019. Accepted for publication Jan 17, 2020.

doi: $10.21037 /$ tau.2020.02.08

View this article at: http://dx.doi.org/10.21037/tau.2020.02.08

\section{Introduction}

Benign prostatic hyperplasia (BPH) is one of the most common clinical problems at urology department which contributes to lower urinary tract symptoms (LUTS) that can range from marginally to significantly impacting quality of life among aging men. Prevalence rates of BPH ranged from $50-75 \%$ among 50 years men, and rose to $80 \%$ among 70 years men and older (1-3). As a target organ of sex hormones, both the development and growth of prostate are 
regulated by androgen and estrogen together. Testosterone (T) levels are highest in twenties men and steadily decline $1-2 \%$ per year thereafter (4). While estrogen levels remain constant or decline slightly, resulting in increasing ratio, of estrogen to androgen in circulating and intraprostatic (5-7).

In 1970s, as we all know, the synergistic effect between estrogen and androgen in inducing glandular prostatic hyperplasia was firstly demonstrated by castrated dog models. Therefore, investigators put forward the hypothesis that estrogen maybe induce prostatic hyperplasia among men too. Effects of estrogen inducing $\mathrm{BPH}$ are mediated through prostatic estrogen receptors alpha $(\mathrm{ER} \alpha)$ and beta $(\mathrm{ER} \beta)$ with expression levels changing over time and with disease progression (8). Nevertheless, the precise molecular mechanisms of BPH development are still unclear. There are only several reports to demonstrate ER expressions in prostate tissues of $\mathrm{BPH}$ patients $(9,10)$, the role of estrogen inducing primary prostate stromal cells proliferation (11-15), and inflammatory expressions in prostate tissues of $\mathrm{BPH}$ patients (16-18). Further investigations are needed to explore the precise molecular mechanisms of BPH, if need.

Thus, this study is aiming to explore ER expressions in prostate tissues of $\mathrm{BPH}$ patients, the role of estrogen inducing primary prostate stromal cells proliferation, and inflammatory expressions in prostate tissues of $\mathrm{BPH}$ patients.

\section{Methods}

\section{Prostate tissue samples collection}

Prostate tissue samples were collected at West China Hospital, Sichuan University, under the procedures approved by the Ethics Committee of West China Hospital, Sichuan University. In total, 44 prostate tissues of $\mathrm{BPH}$ were collected from patients scheduled for transurethral resection of the prostate. Post-operative pathological diagnosis illustrated prostate carcinoma, prostatic intraepithelial neoplasia, or metastatic tumor were excluded. In addition, individuals with urinary infection, bacterial prostatitis, previous administration with $5 \alpha$-reductase inhibitors, or recurrent BPH were excluded. One breast cancer tissue as positive control of ER, confirmed through post-operative pathological diagnosis, was collected from the patient scheduled for radical mastectomy.

\section{Primary prostate stromal cell culture}

The procedure of primary prostate stromal cell culture was performed as described previously (19). Primary prostate stromal cells were maintained in dulbecco's modified eagle medium (DMEM) supplemented with $10 \%$ or $2 \%$ fetal bovine serum (FBS), $100 \mathrm{IU}$ penicillin and $0.1 \mathrm{mg} / \mathrm{mL}$ streptomycin at $37^{\circ} \mathrm{C}$ in $5 \% \mathrm{CO}_{2}$.

\section{Cell proliferation assays}

Cell proliferation was analyzed with the cell count kit-8 (CCK-8) assay. Primary prostate stromal cells were seeded in 96 well plates in quadruplicate at a density of 5,000 cells per well respectively in DMEM supplemented with $10 \%$ or $2 \%$ fetal bovine serum, $100 \mathrm{IU}$ penicillin and $0.1 \mathrm{mg} / \mathrm{mL}$ streptomycin, and treated with different concentration estrogen for 1, 2 and 3 days (20). Then, 96 well plates were incubated for 2 hours at $37^{\circ} \mathrm{C}$ in $5 \% \mathrm{CO}_{2}$ after added CCK-8 $(10 \mu \mathrm{L}$ per well), and detected optical density (OD) at $450 \mathrm{~mm}$. To keep estrogen levels constant, the medium was refreshed every 24 hours. Estrogen and fulvestrant were purchased from Sigma.

\section{Western blot analysis}

Protein extracts were resolved by sodium dodecyl sulfate polyacrylamide gel electrophoresis (SDS-PAGE) and indicated primary antibodies were used. ER $\alpha$ antibody was purchased from Gene Company, Hong Kong. ERßantibody was purchased from BioGnex, Canada. GAPDH antibody was purchased from Abcam. C-C chemokine receptor type 4 (CCR4), C-C chemokine receptor type 3 (CCR3), CD40 ligand (CD40L) and interleukin 10 (IL10) antibodies were purchased from Cell Signaling Technology (CST), as well as SDS-PAGE.

\section{Quantitative real-time polymerase chain reaction ( $q P C R$ )}

Total RNAs were extracted using TRIzol reagent bought from Invitrogen Technology and stored at $-80^{\circ} \mathrm{C}$. RNeasy MinElute ${ }^{\mathrm{TM}}$ reagent was purchased from Qiagen Technology. PCR primers used were summarized in Table 1.

\section{Statistics}

All data analysis was performed with GraphPad Prism Version 6.0 for Windows (GraphPad Software, California, USA). Two-tailed $t$-test analysis was used to analyze continuous data. $\mathrm{P}<0.05$ was considered as significant. 
Table 1 Primer sequences for quantitative real-time polymerase chain reaction (qPCR) analysis

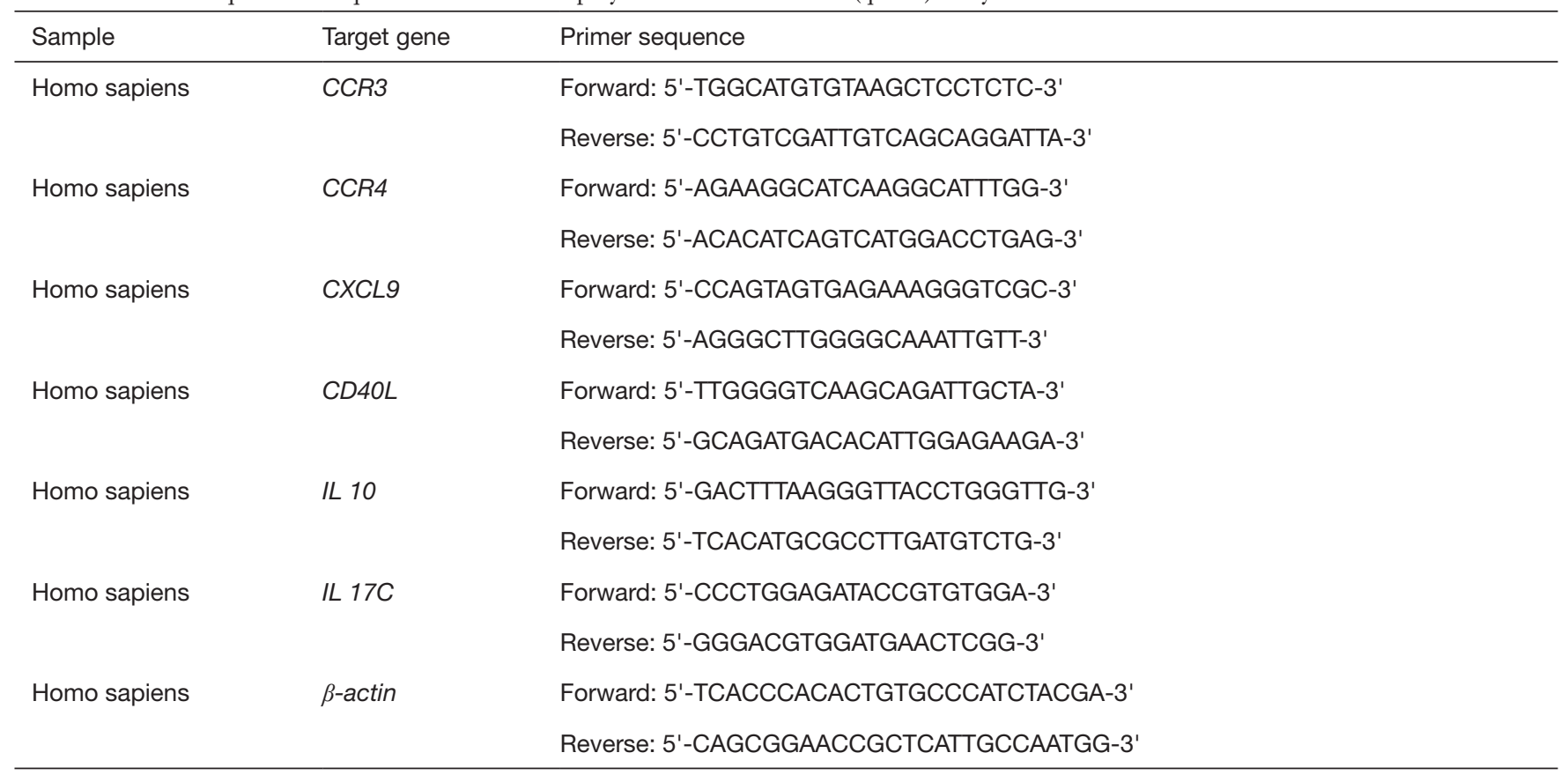

CCR3, C-C chemokine receptor type 3; CCR4, C-C chemokine receptor type 4; CXCL9, C-X-C motif chemokine ligand 9; CD40L, C-X-C motif chemokine ligand 9; IL10, interleukin 10; IL17C, interleukin 17C.

\section{Results}

\section{ER expressions in prostate tissues}

A total of 44 prostate tissues from BPH patients administrated with transurethral resection of the prostate were collected to investigate ER expressions through immunohistochemistry (IHC). In all specimens, ER $\alpha$ was negative (Figure 1A,B). Then, $\mathrm{ER} \alpha$ was positive in breast cancer tissue (Figure 1C,D). ER $\beta$ was positive (Figure 1E) in all samples, and ER $\beta$ was mainly located in nucleuses of epithelial cells and stromal cells (Figure $1 F$ ).

\section{Effects of different concentration estrogen on primary prostate stromal cells growth}

To verify the significant role of estrogen in the pathogenesis of BPH, the effects of estrogen on the growth of primary prostate stromal cells in culture were detected. Proliferation of primary prostate stromal cells maintained in DMEM supplemented with $10 \% \mathrm{FBS}$ was not changed by $10^{-9}$ to $10^{-5} \mathrm{~mol} / \mathrm{L}$ estrogen up to 3 days (Figure $2 A$ ). Nevertheless, Proliferation of primary prostate stromal cells was promoted by estrogen $\left(10^{-7}, 10^{-8}\right.$ and $\left.10^{-9} \mathrm{~mol} / \mathrm{L}\right)$ at the third day when the DMEM was supplemented with $2 \%$ FBS $(\mathrm{P}<0.01$,
$\mathrm{P}<0.05$ and $\mathrm{P}<0.01$, respectively) (Figure $2 B$ ). Therefore, estrogen, especially $10^{-7} \mathrm{~mol} / \mathrm{L}$ estrogen, significantly promotes primary prostate stromal cells proliferation when primary prostate stromal cells were maintained in DMEM supplemented with $2 \%$ FBS.

To confirm whether the effect of estrogen stimulating primary prostate stromal cells proliferation was mediated by ER, primary prostate stromal cells were administrated with estrogen plus fulvestrant $\left(10^{-7} \mathrm{~mol} / \mathrm{L}\right)$. Results demonstrated that the effect of estrogen-mediated primary prostate stromal cells proliferation could be significantly inhibited by fulvestrant $(\mathrm{P}<0.001)$ (Figure $2 C)$.

\section{Estrogen and fulvestrant regulating the expressions of inflammatory in primary prostate stromal cells}

To explore the expressions of inflammatory genes of primary prostate stromal cell were regulated by estrogen and fulvestrant. Primary prostate stromal cells were treated with estrogen $\left(10^{-7} \mathrm{~mol} / \mathrm{L}\right)$ or estrogen $\left(10^{-7} \mathrm{~mol} / \mathrm{L}\right)$ plus fulvestrant $\left(10^{-7} \mathrm{~mol} / \mathrm{L}\right)$ for 1 day or 3 days and harvested for qPCR analysis. We first compared mRNA levels among the groups. Interestingly, we found that there are significantly lower of CCR4 and IL17C mRNA levels in estrogen 



Figure 1 Immunohistochemistry (IHC) analysis of ER in human benign prostatic hyperplasia (BPH) individuals and human breast cancer cases. (A,B) ER $\alpha(-)$ in BPH ( $\times 100$ and $\times 200$, respectively); (C,D) ER $\alpha(+)$ in breast cancer $(\times 100$ and $\times 200$, respectively); (E) ER $\beta(+)$ in BPH ( $\times 100)$; (F) ERßmainly located in nucleuses of epithelial cells and stromal cells $(\times 200)$.

group and estrogen plus fulvestrant group than control group (all $\mathrm{P}<0.05$ ) (Figure $3 A, B)$, which demonstrated that CCR4 and IL17C mRNA levels could be down-regulated by estrogen, and this down-regulation effect could be partly inhibited by fulvestrant. Nevertheless, we found that there are significantly higher of CCR3, CD 40L, C-X-C motif chemokine ligand 9 (CXCL9) and IL10 mRNA levels in estrogen group than control group (all $\mathrm{P}<0.05$ ) (Figure $3 C, D, E, F)$. Furthermore, the effects could be significantly inhibited by fulvestrant, of estrogen upregulating the mRNA levels of CCR3, CD 40L, CXCL9 and IL10 (all $\mathrm{P}<0.05$ ) (Figure 3C,D,E,F).

Then, IHC was performed to confirm the expressions of inflammatory CCR3, CCR4, CD40L, IL10, IL17 and
CXCL9 in primary prostate stromal cells cultured to the third generation (Figure 4). IHC results indicated that the expressions of CCR3, CCR4, CD40L, IL10 and IL17 were positive in the third-generation primary prostate stromal cells, and CXCL9 was negative in the third-generation primary prostate stromal cells.

To validate the findings based on qPCR and IHC analyses, primary prostate stromal cells were treated with estrogen $\left(10^{-7} \mathrm{~mol} / \mathrm{L}\right)$ or estrogen $\left(10^{-7} \mathrm{~mol} / \mathrm{L}\right)$ plus fulvestrant $\left(10^{-7} \mathrm{~mol} / \mathrm{L}\right)$ for 1 to 3 days and harvested for western blot analysis. Western blot was performed to investigate protein levels of CCR4, CCR3, CD40L and IL10 (Figure 5A). Quantitative analysis of protein levels of CCR4, CCR3, CD40L and IL10 was shown in 
A

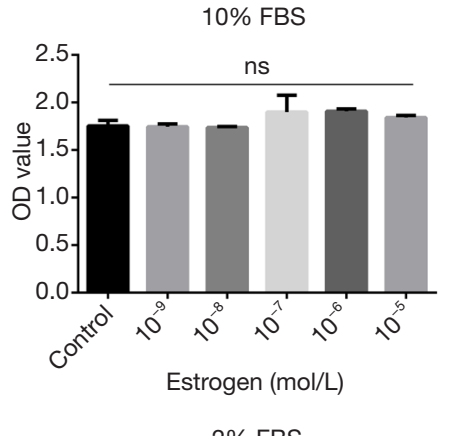

B



$2 \%$ FBS



Figure 2 Effects of estrogen and fulvestrant on proliferation of prostate stromal cells in primary culture supplemented with $10 \%$ FBS or 2\% FBS. (A) Estrogen not stimulates the proliferation of stromal cells supplemented with 10\% FBS for 3 days; (B) estrogen $\left(10^{-7}, 10^{-8}\right.$ and $\left.10^{-9} \mathrm{~mol} / \mathrm{L}\right)$ stimulates the proliferation of stromal cells supplemented with $2 \%$ FBS at the third day; (C) fulvestrant $\left(10^{-7} \mathrm{~mol} / \mathrm{L}\right)$ significantly inhibited the effect of estrogen $\left(10^{-7} \mathrm{~mol} / \mathrm{L}\right)$ stimulating the proliferation of primary prostate stromal cells. ${ }^{*} \mathrm{P}<0.05,{ }^{* *} \mathrm{P}<0.01,{ }^{* * *} \mathrm{P}<0.001$. ns, not significant. FBS, fetal bovine serum.

Figure $5 B, C, D, E$. Firstly, in estrogen group, protein level of CD40L gradually increased from the first day to the third day. Nevertheless, protein levels of CCR3, CCR4 and IL10 gradually increased from the first day to the second day, then gradually decreased from the second day to the third day. Then, the results showed that the protein levels of CD40L and IL10 were significantly higher in estrogen group compared with control group, estrogen plus fulvestrant group at the first day, second day and third day (all $\mathrm{P}<0.05$ ). Therefore, we predicted that the effects could be partially inhibited by fulvestrant, of estrogen upregulating the protein levels of CD40L and IL10.

\section{Discussion}

$\mathrm{BPH}$ is a common disorder of aging male, which may cause lower urinary tract symptoms (LUTS) and affect the quality life of patients. As all we know, age and androgen are considered as the main etiology of $\mathrm{PBH}$. Then, what should we pay close attention to is that estrogen/androgen imbalance associated with aging maybe play a marked role in the development of BPH. The study of Roberts et al. (21) illustrated that the estrogen/androgen ratio increased from $0.042,0.044$, to 0.050 among men aged $<60,60-69$, and $>69$ years $(\mathrm{P}=0.04)$. Recently, although studies demonstrated that estrogen plays a potential role in the pathogenesis of $\mathrm{BPH}$, the exact molecular role of estrogen in the development of BPH is still unclear (22-24).

Effects of estrogen inducing BPH are mediated through prostatic ER $\alpha$ and ER $\beta$. Nevertheless, diverse studies demonstrated different results in terms of the location of $\mathrm{ER} \alpha$ and $\mathrm{ER} \beta$ in human prostate $(9,20,25,26)$. In our study, ER $\alpha$ was negative, and ER $\beta$ was positive in 44 prostate tissues of BPH patients. What's more, the 44 prostate tissues of BPH patients for ER $\alpha$ and $\mathrm{ER} \beta$ analysis by IHC were collected from patients scheduled for transurethral resection of the prostate. Thus, the prostate tissues for $\mathrm{ER} \alpha$ and ER $\beta$ analyses by IHC in our study are from the transition zone of prostate rather than peripheral zone of prostate. Furthermore, our results shared a number of similarities with Tsurusaki et al.'s findings that ER $\alpha$ expression was restricted to stromal cells of peripheral zone, and ER $\beta$ was expressed in the stromal cells and epithelial cells of peripheral zone as well as transition zone (25). The results of this study illustrated that the expressions of ER $\alpha$ and $\mathrm{ER} \beta$ are zone-dependent in prostate tissues of $\mathrm{BPH}$ individuals.

Compared with non-BPH individuals, $\mathrm{BPH}$ cases are characterized by increased prostate stromal volume $(4,11)$. Furthermore, Ho et al. (20) investigated the effects of estrogen on the proliferation of BPH-derived prostate cells in culture, which revealed that estrogen increased the proliferation of prostate stromal cells rather than prostate epithelial cells. Thus, primary prostate stromal cells were cultured to investigate the effects of estrogen 

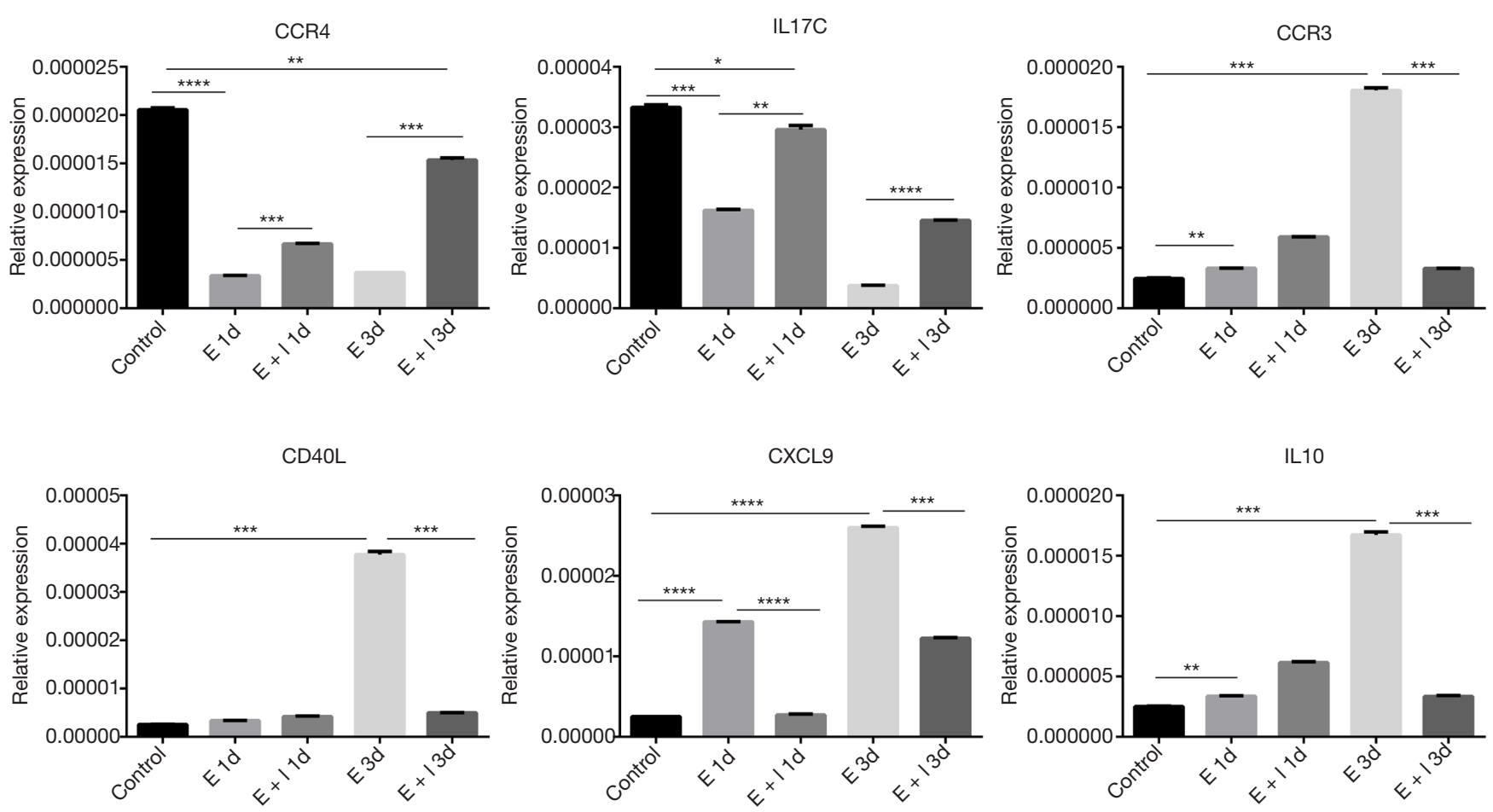

Figure 3 The expression levels of CCR3, CCR4, CD40L, CXCL9, IL10 and IL17C mRNA in primary prostate stromal cells. (A,B) CCR4 and IL17C mRNA levels were down-regulated by estrogen; (C,D,E,F) CCR3, CD40L, CXCL9 and IL10 mRNA levels were up-regulated by estrogen, and inhibited by fulvestrant. ${ }^{*} \mathrm{P}<0.05$, ${ }^{* *} \mathrm{P}<0.01$, ${ }^{* * *} \mathrm{P}<0.001$, ${ }^{* * *} \mathrm{P}<0.0001$. E, estrogen; I, inhibitor; CCR4, C-C chemokine receptor type 4; CCR3, C-C chemokine receptor type 3; CD40L, CD40 ligand; CXCL9, C-X-C motif chemokine ligand 9; IL10, interleukin 10; IL17C, interleukin 17C.

regulating cells proliferation and inflammatory expression of primary prostate stromal cells in this study. In addition, it was consistent with previous finding (20) that estrogen, especially $10^{-7} \mathrm{~mol} / \mathrm{L}$ estrogen, significantly promotes primary prostate stromal cells proliferation when primary prostate stromal cells were maintained in DMEM supplemented with $2 \%$ FBS. Last but not least, the effect of estrogen reinforcing primary prostate stromal cells proliferation was significantly inhibited by fulvestrant in our study.

The significance of inflammation in BPH and LUTS has been manifested by the longitudinal results of the Medical Therapies of Prostate Symptoms (MTOPS) study, which revealed that stronger inflammation in the transitional zone of prostate was associated with the progression of LUTS and incidence of acute urinary retention (12). Furthermore, previous study demonstrated that the increase of IL17 in BPH tissue was associated with IL6 and IL8, the key factors of prostate stromal cells hyperplasia $(13,18,27)$. Thus, it was investigated that both estrogen and fulvestrant regulate the expressions of inflammatory of primary prostate stromal cells in our study. We found that the expression of CCR4 and IL17C mRNA levels could be down-regulated by estrogen, and the down-regulation effect could be partly inhibited by fulvestrant. Nevertheless, we found that there are significantly higher of CCR3, CD 40L, CXCL9 and IL10 mRNA levels in estrogen group than control group. Yoo et al. (14) reported that there is a strong association between IL10 and BPH in Korean population. Furthermore, other studies have illustrated that both chronic inflammation and immune dysregulation play significant roles in the progression of BPH $(15,28,29)$. Finally, further studies are needed to explore molecular mechanisms and signal pathways activated by estrogen in the pathogenesis of BPH.

This study has several limitations. Firstly, in our study, the 44 prostate tissues of $\mathrm{BPH}$ patients for $\mathrm{ER} \alpha$ and $\mathrm{ER} \beta$ analysis mainly included the transition zone rather than peripheral zone because the 44 prostate tissues of $\mathrm{BPH}$ patients for $\mathrm{ER} \alpha$ and $\mathrm{ER} \beta$ analysis by IHC were collected 

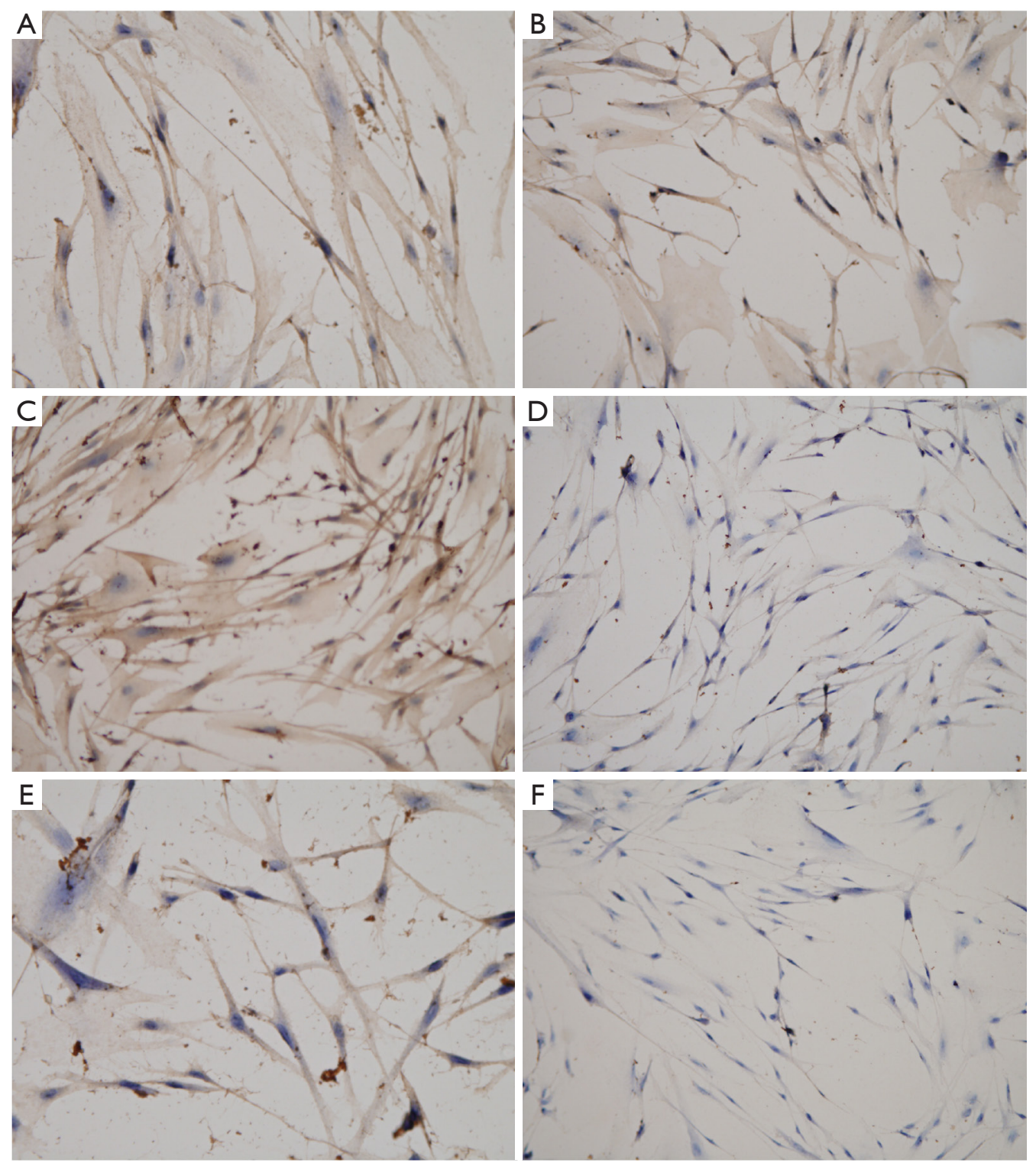

Figure 4 IHC analysis of CCR3, CCR4, CD4OL, CXCL9, IL10 and IL17C in primary prostate stromal cells. CCR3, CCR4, CD40L, IL10 and IL17 was positive (A,B,C,D,E), and CXCL9 was negative $(\mathrm{F})(\times 200)$. IHC, Immunohistochemistry; CCR3, C-C chemokine receptor type 3; CCR4, C-C chemokine receptor type 4; CD40L, CD40 ligand; CXCL9, C-X-C motif chemokine ligand 9; IL10, interleukin 10; IL17C, interleukin 17C.

from patients scheduled for transurethral resection of the prostate. Therefore, the results of the expression of $\mathrm{ER} \alpha$ and $\mathrm{ER} \beta$ in our study only represent the transition zone of prostate, and further study is needed to explore the expression of ER $\alpha$ and ER $\beta$ in the peripheral zone of prostate among $\mathrm{BPH}$ individuals. Secondly, it was not elaborated in our study that the precise molecular mechanisms and signal pathways of estrogen regulating cells proliferation and expression of inflammatory in primary prostate stromal cells, and further studies are needed to explore precise molecular mechanisms and signal pathways.

\section{Conclusions}

Firstly, ER $\beta$ was positive, and ER $\alpha$ was negative in the 
A
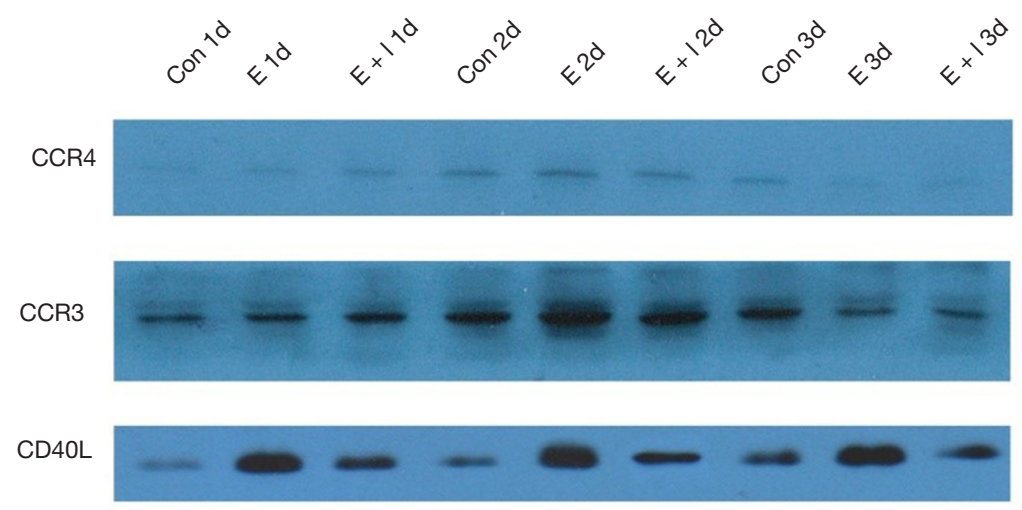

IL 10

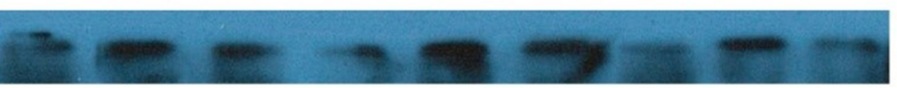

GAPDH



B

CCR4



CD4OL

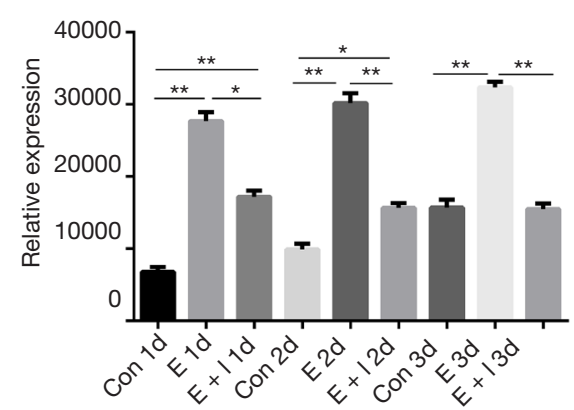

CCR3

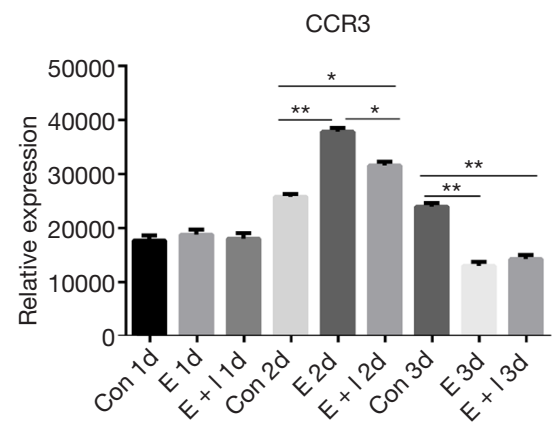

IL 10

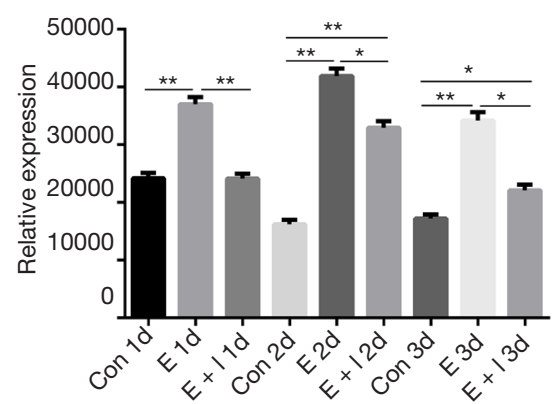

Figure 5 Protein levels of CCR4, CCR3, CD40L and IL10 in primary prostate stromal cells (A). Quantitative analysis of protein levels of CCR4, CCR3, CD40L and IL10 (B-E). ${ }^{*} \mathrm{P}<0.05$, ${ }^{* *} \mathrm{P}<0.01$. E, estrogen; I, inhibitor. CCR4, C-C chemokine receptor type 4; CCR3, C-C chemokine receptor type 3; CD40L, CD40 ligand; IL10, interleukin 10.

transition zone of prostate. Secondly, the effects could be partially inhibited by fulvestrant, of estrogen promoting the proliferation of primary prostate stromal cells cultured in DMEM supplemented with 2\% FBS. Thirdly, estrogen upregulates the mRNA levels of CCR3, CD 40L, CXCL9 and
IL10, and down-regulates the mRNA levels of CCR4 and IL17C. Then, the expressions of CCR3, CCR4, CD40L, IL10 and IL17 are positive, and CXCL9 was negative in the third-generation primary prostate stromal cells. Finally, the effects could be partially inhibited by fulvestrant, 
of estrogen up-regulating the protein levels of CD40L and IL10.

\section{Acknowledgments}

Funding: This research was funded by the National Natural Science Foundation of China (Grant no. 81370855, 81770857 and 81200551) and Project of Sichuan Province Science and Technology Department (Grant no. 2015SZ0230 and 2017KJT0034).

\section{Footnote}

Conflicts of Interest: All authors have completed the ICMJE uniform disclosure form (available at http://dx.doi. org/10.21037/tau.2020.02.08). The authors have no conflicts of interest to declare.

Ethical Statement: The authors are accountable for all aspects of the work in ensuring that questions related to the accuracy or integrity of any part of the work are appropriately investigated and resolved. This study was approved by the Ethics Committee of West China Hospital, Sichuan University. Informed consent was obtained from each recruited patient.

Open Access Statement: This is an Open Access article distributed in accordance with the Creative Commons Attribution-NonCommercial-NoDerivs 4.0 International License (CC BY-NC-ND 4.0), which permits the noncommercial replication and distribution of the article with the strict proviso that no changes or edits are made and the original work is properly cited (including links to both the formal publication through the relevant DOI and the license). See: https://creativecommons.org/licenses/by-nc-nd/4.0/.

\section{References}

1. Egan KB. The Epidemiology of Benign Prostatic Hyperplasia Associated with Lower Urinary Tract Symptoms: prevalence and Incident Rates. Urol Clin North Am 2016;43:289-97.

2. Lokeshwar SD, Harper BT, Webb E, et al. Epidemiology and treatment modalities for the management of benign prostatic hyperplasia. Transl Androl Urol 2019;8:529-39.

3. Zhang $\mathrm{W}$, Zhang $\mathrm{X}, \mathrm{Li} \mathrm{H}$, et al. Prevalence of lower urinary tract symptoms suggestive of benign prostatic hyperplasia (LUTS/BPH) in China: results from the
China Health and Retirement Longitudinal Study. BMJ Open 2019;9:e022792.

4. Rastrelli G, Vignozzi L, Corona G, et al. Testosterone and Benign Prostatic Hyperplasia. Sex Med Rev 2019;7:259-71.

5. Chang WH, Tsai YS, Wang JY, et al. Sex hormones and oxidative stress mediated phthalate-induced effects in prostatic enlargement. Environ Int 2019;126:184-92.

6. Miao L, Jiao C, Shao R, et al. Bakuchiol suppresses oestrogen/testosterone-induced Benign Prostatic Hyperplasia development through up-regulation of epithelial estrogen receptor $\beta$ and down-regulation of stromal aromatase. Toxicol Appl Pharmacol 2019;381:114637.

7. Asiedu B, Anang Y, Nyarko A, et al. The role of sex steroid hormones in benign prostatic hyperplasia. Aging Male 2017;20:17-22.

8. Prins GS, Korach KS. The role of estrogens and estrogen receptors in normal prostate growth and disease. Steroids 2008;73:233-44.

9. Song L, Shen W, Zhang H, et al. Differential expression of androgen, estrogen, and progesterone receptors in benign prostatic hyperplasia. Bosn J Basic Med Sci 2016;16:201-8.

10. Yang DL, Xu JW, Zhu JG, et al. Role of GPR30 in estrogen-induced prostate epithelial apoptosis and benign prostatic hyperplasia. Biochem Biophys Res Commun 2017;487:517-24.

11. Fibbi B, Penna G, Morelli A, et al. Chronic inflammation in the pathogenesis of benign prostatic hyperplasia. Int $\mathrm{J}$ Androl 2010;33:475-88.

12. Torkko KC, Wilson RS, Smith EE, et al. Prostate Biopsy Markers of Inflammation are Associated with Risk of Clinical Progression of Benign Prostatic Hyperplasia: Findings from the MTOPS Study. J Urol 2015;194:454-61.

13. Steiner GE, Newman ME, Paikl D, et al. Expression and function of pro-inflammatory interleukin IL-17 and IL17 receptor in normal, benign hyperplastic, and malignant prostate. Prostate 2003;56:171-82.

14. Yoo KH, Kim SK, Chung JH, et al. Association of IL10, IL10RA, and IL10RB polymorphisms with benign prostate hyperplasia in Korean population. J Korean Med Sci 2011;26:659-64.

15. Vignozzi L, Cellai I, Santi R, et al. Antiinflammatory effect of androgen receptor activation in human benign prostatic hyperplasia cells. J Endocrinol 2012;214:31-43.

16. Paterniti I, Campolo M, Cordaro M, et al. Effects of different natural extracts in an experimental model 
of benign prostatic hyperplasia (BPH). Inflamm Res 2018;67:617-26.

17. Huang TR, Wang GC, Zhang HM, et al. Differential research of inflammatory and related mediators in $\mathrm{BPH}$, histological prostatitis and PCa. Andrologia 2018. [Epub ahead of print].

18. Xu D, Chen P, Xiao H, et al. Upregulated Interleukin 21 Receptor Enhances Proliferation and EpithelialMesenchymal Transition Process in Benign Prostatic Hyperplasia. Front Endocrinol (Lausanne) 2019;10:4.

19. Liu LR, Liu ZH, Wei Q. Primary culture of benign prostatic hyperplasia stromal cell. Sichuan Da Xue Xue Bao Yi Xue Ban 2010;41:518-22.

20. Ho CK, Nanda J, Chapman KE, et al. Oestrogen and benign prostatic hyperplasia: effects on stromal cell proliferation and local formation from androgen. J Endocrinol 2008;197:483-91.

21. Roberts RO, Jacobson DJ, Rhodes T, et al. Serum sex hormones and measures of benign prostatic hyperplasia. Prostate 2004;61:124-31.

22. De Nunzio C, Kramer G, Marberger M, et al. The controversial relationship between benign prostatic hyperplasia and prostate cancer: the role of inflammation. Eur Urol 2011;60:106-17.

23. Jeyaraj DA, Udayakumar TS, Rajalakshmi M, et al. Effects of long-term administration of androgens and estrogen on rhesus monkey prostate: possible induction of benign

Cite this article as: Chen B, Cao D, Chen Z, Huang Y, Lin T, Ai J, Liu L, Wei Q. Estrogen regulates the proliferation and inflammatory expression of primary stromal cell in benign prostatic hyperplasia. Transl Androl Urol 2020;9(2):322-331. doi: 10.21037/tau.2020.02.08 prostatic hyperplasia. J Androl 2000;21:833-41.

24. Zhou Y, Xiao XQ, Chen LF, et al. Proliferation and phenotypic changes of stromal cells in response to varying estrogen/androgen levels in castrated rats. Asian J Androl 2009; 11:451-59.

25. Tsurusaki T, Aoki D, Kanetake H, et al. Zone-dependent expression of estrogen receptors alpha and beta in human benign prostatic hyperplasia. J Clin Endocrinol Metab 2003;88:1333-40.

26. Gangkak G, Bhattar R, Mittal A, et al. Immunohistochemical analysis of estrogen receptors in prostate and clinical correlation in men with benign prostatic hyperplasia. Investig Clin Urol 2017;58:117-26.

27. Arivazhagan J, Nandeesha H, Dorairajan LN, et al. Association of elevated interleukin-17 and angiopoietin-2 with prostate size in benign prostatic hyperplasia. Aging Male 2017;20:115-18.

28. Chiang BJ, Kuo HC, Liao CH. Can Botulinum Toxin A Still Have a Role in Treatment of Lower Urinary Tract Symptoms/Benign Prostatic Hyperplasia Through Inhibition of Chronic Prostatic Inflammation. Toxins (Basel) 2019. doi: 10.3390/toxins11090547.

29. Pang Y, Li H, Gong Y, et al. Association of CCL2, CCR2 and CCL5 genetic polymorphisms with the development and progression of benign prostatic hyperplasia. Oncol Rep 2019;41:2491-501. 